\title{
Significance of exercise-induced second degree atrioventricular block
}

\author{
A. Bakst, B. Goldberg, and L. Schamroth \\ From the Baragwanath Hospital, General Hospital, and the University of the Witwatersrand, fohannesburg, \\ S.A.
}

A case of second degree, type II, atrioventricular block precipitated by exercise is presented. It is suggested that exercise and other vagolytic manoeuvres may be used as a means of differentiating type I from type II atrioventricular block: the conduction disturbance of type I improves with exercise, whereas that of type II deteriorates with exercise.

Type I second degree atrioventricular block (the Wenckebach phenomenon) is characterized by consecutive prolongation of atrioventricular conduction times before an impulse is blocked. The lesion is usually in the atrioventricular node, but may on occasion be sited more distally in the conducting system. Type II second degree atrioventricular block is characterized by constant atrioventricular conduction times before an impulse is blocked. The lesion is infranodal.

Vagolytic effect, as mediated, for example, by exercise or the administration of atropine, tends to improve or abolish type I second degree atrioventricular nodal block. It has no such effect on type II second degree atrioventricular block because the more distally sited lesion is beyond vagal influence. A vagolytic effect may, however, aggravate or precipitate type II second degree block by increasing the sinus rate without a concomitant shortening of the refractory period of the relevant atrioventricular conducting tissue. This principle has rarely been commented upon, and is exemplified by the following case.

\section{Case report}

A 74-year-old woman presented with a 2-week history of dyspnoea and extreme weakness on walking. This was so severe that she often had to stop and rest. She had no chest pain but was conscious of a forceful heartbeat. She felt nauseated with the weakness. She had had transient dizzy spells for several years. These would last a few minutes, and occurred at any time. The remainder of the history was non-contributory. Examination revealed an alert, elderly woman. Her blood pressure was $130 / 90 \mathrm{mmHg}(17.3 / 12.0 \mathrm{kPa})$ in both arms, and there were no bruits in the neck. There was no clinical cardiomegaly. A grade 3/6 early-midsystolic murmur was heard at the left sternal border and at the apex, but was not heard in the neck or axilla. There was a trace of ankle oedema. The jugular venous pressure was not raised and there was no hepatomegaly. The chest was clear.

The conventional I2-lead electrocardiogram (Fig. I) shows the features of anteroseptal and 'high' lateral 'ischaemia', as evidenced by the inverted $T$ waves in leads VI to V4, standard lead I, and lead aVL. There is a wide frontal plane QRS-T angle of IIs degrees: the mean manifest QRS axis is directed at o degree; the mean manifest frontal plane $T$ wave axis is directed at + II5 degrees. There is also some prolongation of the horizontal part of the ST segment with a sharp-angled ST-T junction in leads V5 and V6, standard lead III, and lead aVF. The PR interval is prolonged and measures $0.24 \mathrm{~s}$. Long tracings were recorded with the patient at rest (exemplified by tracing $\mathbf{A}$ of Fig. 2), after the administration of atropine (tracing B of Fig. 2), and after exercise (tracing $\mathrm{C}$ of Fig. 2). The PR interval of all conducted beats during rest, after exercise, and after the administration of atropine was constant at $0.24 \mathrm{~s}$. In addition, mild exercise or the administration of atropine precipitated type II second degree atrioventricular block. This occurred when the induced sinus tachycardia resulted in a PP interval shorter than a critical range of $0.82 \mathrm{~s}$ to $0.84 \mathrm{~s}$.

\section{Discussion}

Type II second degree atrioventricular block is evident from the constancy of the PR interval both before and after the blocked impulse. It is further corroborated by the fact that the PR intervals never varied but remained constant under the vagolytic influence of exercise or atropine.

An increase in sinus rate is normally associated 


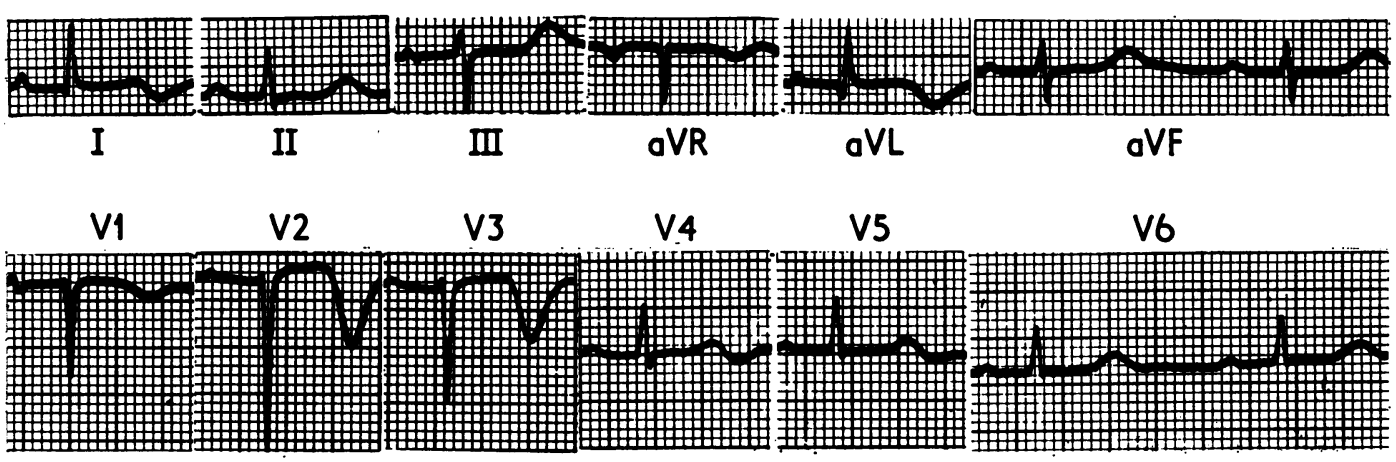

FIG. I Electrocardiogram showing the features of anteroseptal and 'high' lateral 'ischaemia'. See text.

with a concomitant shortening of the atrioventricular nodal refractory period. This enables a $\mathrm{I}: \mathrm{I}$ ventricular response at the relatively high rates of the sinus tachycardia, and thus constitutes a physiological phenomenon.

The infranodal or distal conducting system is not under vagal influence and thus its refractory period cannot shorten with vagolytic manoeuvres. This may possibly shorten with sympathomimetic influence resulting from the exercise. It is thus evident that the refractory period of the distal conducting system must normally be considerably shorter than that of the atrioventricular node and shorter than the shortest atrioventricular nodal refractory period which occurs with exercise. If this were not so, the shortening of the atrioventricular nodal refractory period with exercise would be to no avail in facilitating a I : I ventricular response, for if the refractory period of the distal conducting system remained con- stant and relatively long (longer than the shortened PP interval) atrioventricular block would be precipitated. If, therefore, second degree atrioventricular block is precipitated during physiological sinus tachycardia, the following conclusions can be drawn:

I) The refractory period of the relevant conducting system is not under vagal influence.

2) It is very likely that the block is infranodal, i.e. in the distal conducting system - in the bundle of His proper. A lesion in the atrioventricular node giving rise to first and second degree atrioventricular block would be expected to retain sufficient vagal potential to shorten with vagolytic influence.

The effect of changes in sinus rate upon type II atrioventricular block is rarely commented upon. Spang (1957) observed that the small fluctuations in
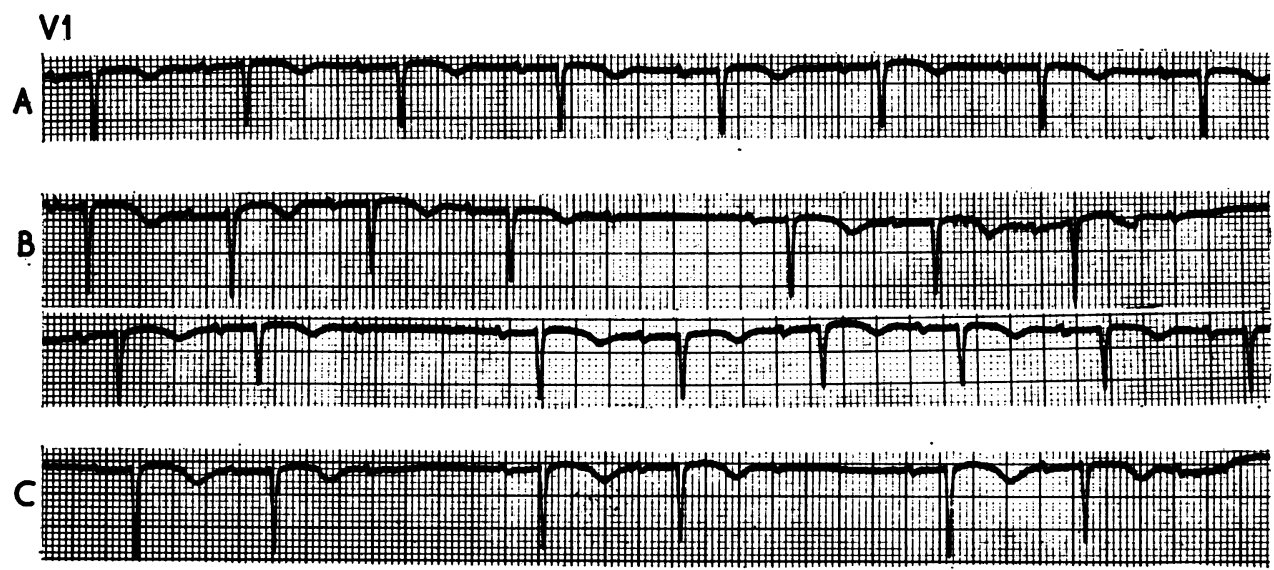

FIG. 2 Electrocardiogram: $A$ ) recorded with the patient at rest; $B$ ) (continuous strip) recorded after the administration of atropine; and $C$ ) recorded after exercise. 
sinus rate during sinus arrhythmia did not have any effect on the constancy of the PR intervals in Mobitz type II atrioventricular block, affecting the PR intervals neither before nor after the dropped beat. Moulopoulos and Anthopoulos (1968) observed that a basic first degree atrioventricular block may occasionally be converted to more advanced degree atrioventricular block by means of exercise. Recently, Goodfriend and Barold (1974) reported a case of tachycardia-dependent and bradycardiadependent type II atrioventricular block with narrow QRS complexes. His bundle recording studies revealed the lesion to be above the level of origin of the His spike, and below the level of the atrioventricular node.

It was Gilchrist (1958) who first advocated the use of exercise as a means of differentiating type I from type II atrioventricular block; the conduction disturbance of type I improves with exercise whereas that of type II deteriorates with exercise.
This principle is worthy of emphasis and is evident from the present case.

\section{References}

Gilchrist, A. R. (1958). Clinical aspects of high-grade heartblock. Scottish Medical fournal, 3, 53.

Goodfriend, M. A., and Barold, S. S. (1974). Tachycardiadependent and bradycardia-dependent Mobitz Type II atrioventricular block within the bundle of His. American fournal of Cardiology, 33, 908.

Moulopoulos, S. D., and Anthopoulos, L. P. (1968). Reversible atrio-ventricular conduction changes during exercise. Acta Cardiologica, 23, 352.

Spang, K. (1957). Rhythmusstorungen des Herzens. Systematik, Ursache und klinische Bedeutung Therapie, pp. 24I-245. George Thieme Verlag, Stuttgart.

Requests for reprints to Professor L. Schamroth, Department of Medicine, Medical School, University of the Witwatersrand, Hospital Street, Johannesburg, South Africa. 